Revista Digital Universitaria

Vol. 21, Núm. 4, julio-agosto 2020

\title{
La no revictimización de las mujeres en México
}

Dalia B. Carranco

\section{Resumen}

La violencia contra las mujeres es, lamentablemente, una realidad muy activa en México. Una mujer víctima, aparte del daño que sufre por el delito, tiene dificultades para acceder a la justicia y sufre del perjuicio de la sociedad. En este artículo conoceremos más acerca de la rama que se encarga de estudiar la llamada revictimización y discutiremos cómo evitar hacer un doble, o incluso más, daño a las mujeres víctimas de un delito.

Palabras clave: victimología, victimización, revictimización, igualdad de género, derechos de las mujeres, violencia contra las mujeres, machismo.

\section{Non-reVictimization of Women in Mexico}

\begin{abstract}
Violence against women is, unfortunately, a very active reality in Mexico. A woman victim, aside from the damage she suffers from the crime, has difficulties in accessing justice and suffers from prejudice of society. In this article we will learn more about the branch of study that focuses in the so-called revictimization and we will discuss how to avoid causing double, or even more, harm to women victims of a crime.
\end{abstract}

Keywords: victimology, victimization, revictimization, gender equality, women's rights, violence against women, machismo. 
"La no revictimización de las mujeres en México"

\section{Dalia B. Carranco}

\section{dalia.carranco.a@gmail.com \\ https://orcid.org/0000-0003-2018-8904 \\ @CarrancoDalia \\ https://www.linkedin.com/in/dbcarrancoarenas/}

Estudió la Licenciatura en Derecho en la Universidad Nacional Autónoma de México (UNAM)y la Maestría en Derecho Internacional y Ley Europea, enfocada en Derechos Humanos, en la Universidad de Tilburg, Países Bajos. Ha colaborado en el Instituto de Investigaciones Jurídicas de la unAm, el Instituto Internacional de Victimología de Tilburg, la Comisión Interamericana de Derechos Humanos de la Organización de Estados Americanos (OEA), la Corte Penal Internacional y el International Residual Mechanism for Criminal Tribunals de la Organización de Naciones Unidas (ONu).

Sus líneas de investigación son victimología, participación de víctimas y reparaciones, derecho penal internacional y justicia transicional. 
Para saber más sobre los tipos de violencia contra las mujeres enunciados por la legislación mexicana, léase la Ley General de Acceso de las Mujeres a una Vida Libre de Violencia, del 1 de febrero de 2007.

2 Al respecto, encontramos los siguientes artículos que hablan justamente de este tipo de comentarios donde se culpa a la misma víctima por la agresión o se intenta justificar al perpetuador: "Revictimización, agravio extra que enfrentan las mujeres agredidas", La Jornada, 10 de enero de 2018 y "Revictimización de las mujeres en el Sistema Penal", Cimacnoticias, 20 de octubre de 2015.
¿Cuántas veces no hemos leído un artículo de violencia y/o delitos contra las mujeres? Lamentablemente es algo muy común, tanto que muchas personas se han dejado de impresionar por este tipo de violencia, ${ }^{1}$ además de los feminicidios que existen en México. Igual de desafortunada es la cantidad de comentarios que leemos en redes sociales o escuchamos en la calle, en los cuales se culpa a la víctima: "saliendo a esas horas y sola, se lo buscó ella misma", "también por qué anda vestida asi", "antes que agradezca, le hicieron un favor al acosarla", 2 y muchos otros comentarios, tanto de parte de hombres como de mujeres. Todos estos ejemplos son tan sólo una muestra de la cultura misógina instaurada en la sociedad mexicana.

Con este tipo de opiniones y forma de pensar, es muy difícil que las mujeres víctimas se atrevan a denunciar. En especial cuando también se cuestiona el mismo ataque; por ejemplo, para agresiones sexuales: "¿Y por qué hasta ahora denunció? ¡Si ya pasaron años!" o "Yo creo que es mentira o ni la afectó tanto si apenas lo acusó". Poner en duda el delito mismo o la extensión del daño que tuvo ya es, por sí mismo, un impedimento para las mujeres que buscan obtener justicia. Así, la culpa en la mayoría de las ocasiones es atribuida a las mujeres y, como ya se mencionó, esto tiene raíces en la cultura y educación que recibimos. Pero eso no significa que no podamos hacer algo al respecto, tanto a nivel de leyes y políticas, como a nivel personal.

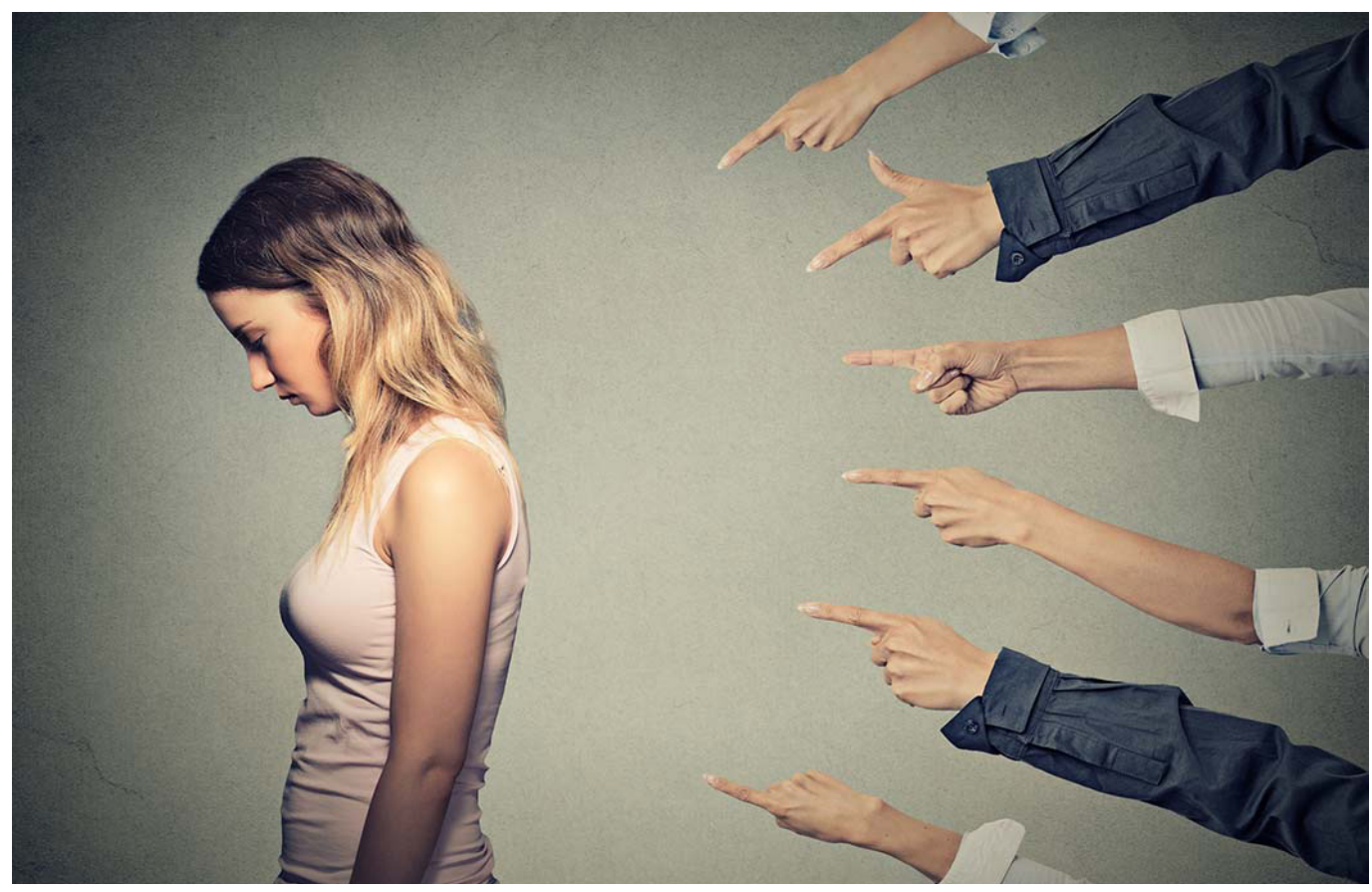

Luego de que se comete un acto criminal, lo que usualmente viene a nuestra mente es sancionar a quien causó la ofensa, tanto así que muchas leyes y políticas están enfocadas en ello. Sin embargo, esto sólo es la mitad del todo, no debemos olvidar que la regulación del derecho tiene el objeto de proteger a los ciudadanos y esto incluye a las víctimas, la otra importantísima cara de la moneda. 
Video 1. ¿Qué es la victimología? (UPV/EHU) 2016)
${ }^{3}$ Se puede encontrar más información relativa a la victimología en los primeros cuatro apartados de Victimología: una visión de sensibilidad y ternura a niñas, niños y adolescentes en tiempos de violencia y delincuencia en México, de María Teresa Ambrosio Morales.
Las víctimas son seres humanos que pasan por situaciones negativas y que quedan indefensas contra las mismas. El Estado tiene la obligación de cuidar que su proceso para obtener justicia y las posibles reparaciones no sean aún más difíciles de lo que ya ha experimentado. De acuerdo con la Organización de las Naciones Unidas, víctima se define como "las personas que, individual o colectivamente, hayan sufrido daños, inclusive lesiones físicas o mentales, sufrimiento emocional, pérdida financiera o menoscabo sustancial de los derechos fundamentales, como consecuencia de acciones u omisiones que violen la legislación penal vigente" (Asamblea General de la Organización de las Naciones Unidas, 1985). Como se ve, se trata de una definición intrínsecamente legal, que sirve a los defensores de justicia.

No obstante, la simple ley hecha por estudiosos del derecho ha probado no ser siempre suficiente. La complejidad del ser humano es tal que la legislación y el derecho no bastan para crear políticas que protejan efectivamente a las víctimas. Se requieren de otras disciplinas con un enfoque diferente del ser humano, como la psicología y sociología. Es decir, se necesitan protocolos con enfoque multidisciplinario, para brindar a las víctimas el mejor entendimiento posible; es así como surge la victimología.

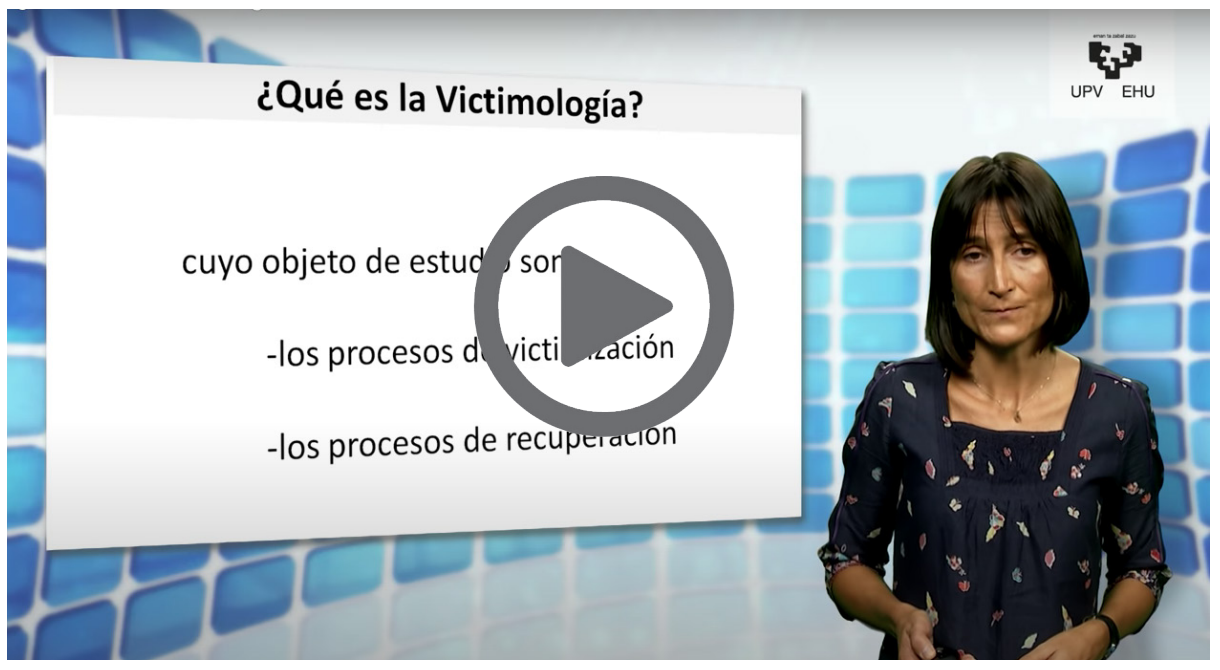

La victimología ${ }^{3}$ no es tan conocida como otras áreas de estudio, a diferencia de la criminología, de la cual tenemos muchas referencias y hasta programas de televisión, donde la manejan como su principal motor. Al igual que la criminología, "está interesada, muy ampliamente hablando, en el estudio de crímenes y delincuentes, [pero] la victimología se enfoca, también ampliamente hablando, en el crimen y sus víctimas" (Dignan, 2005, p.31, ver video 1). La o las víctimas pasan de ser el actor secundario a ser el principal. Ya no son más el personaje pasivo que sufrió un perjuicio, sino toda una entidad humana, con sentimientos, derechos y voz. De acuerdo con Andrew Karmen, poner a las víctimas al centro permite examinar cómo éstas son tratadas por la policía, la fiscalía, los abogados 
y los jueces. Del mismo modo que los criminólogos evalúan la efectividad de los programas de rehabilitación para los criminales, los victimólogos buscan ver el alcance de los problemas emocionales que las víctimas sufren después de un delito. Y, así como los criminólogos intentan calcular el daño económico y social causado por el delincuente, los victimólogos tratan de estimar las perdidas y gastos que las víctimas padecen debido a los hechos ilícitos (2012, p. 18).

De allí la importancia de la victimología que, de acuerdo con la Sociedad Mundial de Victimología, ${ }^{4}$ es el estudio científico del alcance, naturaleza y causas de la victimización criminal, sus consecuencias para las personas involucradas y las reacciones a las mismas por parte de la sociedad, en particular de la policía y el sistema de justicia penal, así como de profesionales y voluntarios en dicho sistema de justicia (citado en Van Dijk, 1997). La victimología busca, pues, visibilizar a la víctima y tomarla como principal sujeto de estudio, para que tanto la legislación como las personas encargadas de ejecutarla tomen las medidas adecuadas a su favor, sin dañarla con acciones u omisiones que le puedan ser perjudiciales. Así, el estudio de la víctima y victimización -y como se verá más adelante de la revictimización - son el centro del estudio de la victimología.

Se le llama victimización al primer acto donde se comete el delito, cuando una persona es agredida. Aquí, a grandes rasgos, surgen dos partes: el perpetrador o criminal y la o las víctimas. Desde ese momento, la persona que padeció el delito ya sufre daños por ese mismo hecho, ya sea físicos, monetarios, psicológicos, etcétera. La revictimización o victimización secundaria se da cuando la misma víctima, aparte del ocasionado por el delito, sufre daño posterior causado por los impartidores de justicia, por la policía, jueces, voluntarios y trabajadores del sistema penal, y por la misma sociedad, incluyendo familiares, comunidades o medios de comunicación. En México, en el Modelo Integral de Atención a Víctimas publicado en el Diario Oficial de la Federación (DOF) se definió revictimización como "un patrón en el que la víctima de abuso y/o de la delincuencia tiene una tendencia significativamente mayor de ser víctimas nuevamente. Se entiende como la experiencia que victimiza a una persona en dos o más momentos de su vida, es decir, la suma de acciones u omisiones que generan en la persona un recuerdo victimizante" (DOF, 2015). Como acciones de prevención a la revictimización se encuentran "el acompañamiento terapéutico, la reconstrucción de redes sociales, diagnósticos y orientación, asî como actividades a largo plazo que impliquen el restablecimiento de los derechos de las víctimas" (DOF, 2015).

En el caso de las víctimas mujeres, muchas de ellas prefieren no denunciar ante las autoridades por diversos motivos, uno de los principales es el temor

${ }^{4}$ En inglés, World Society of Victimology, que es una organización no gubernamental, sin fines de lucro, con estatus consultivo de Categoría Especial ante el Consejo Económico y Social de la Organización de las Naciones Unidas y el Consejo de Europa. que tienen de que las personas encargadas de escucharlas y permitirles el acceso a la justicia las agredan con una serie de comentarios que las hagan sentir violentadas y poco protegidas. Y es que muchos servidores públicos no suelen tener una educación enfocada a la no revictimización y tienden a agredir con comentarios inadecuados a las víctimas. Aún más, algunos buscan la causa del delito en las acciones de la víctima, justificando al perpetrador. 


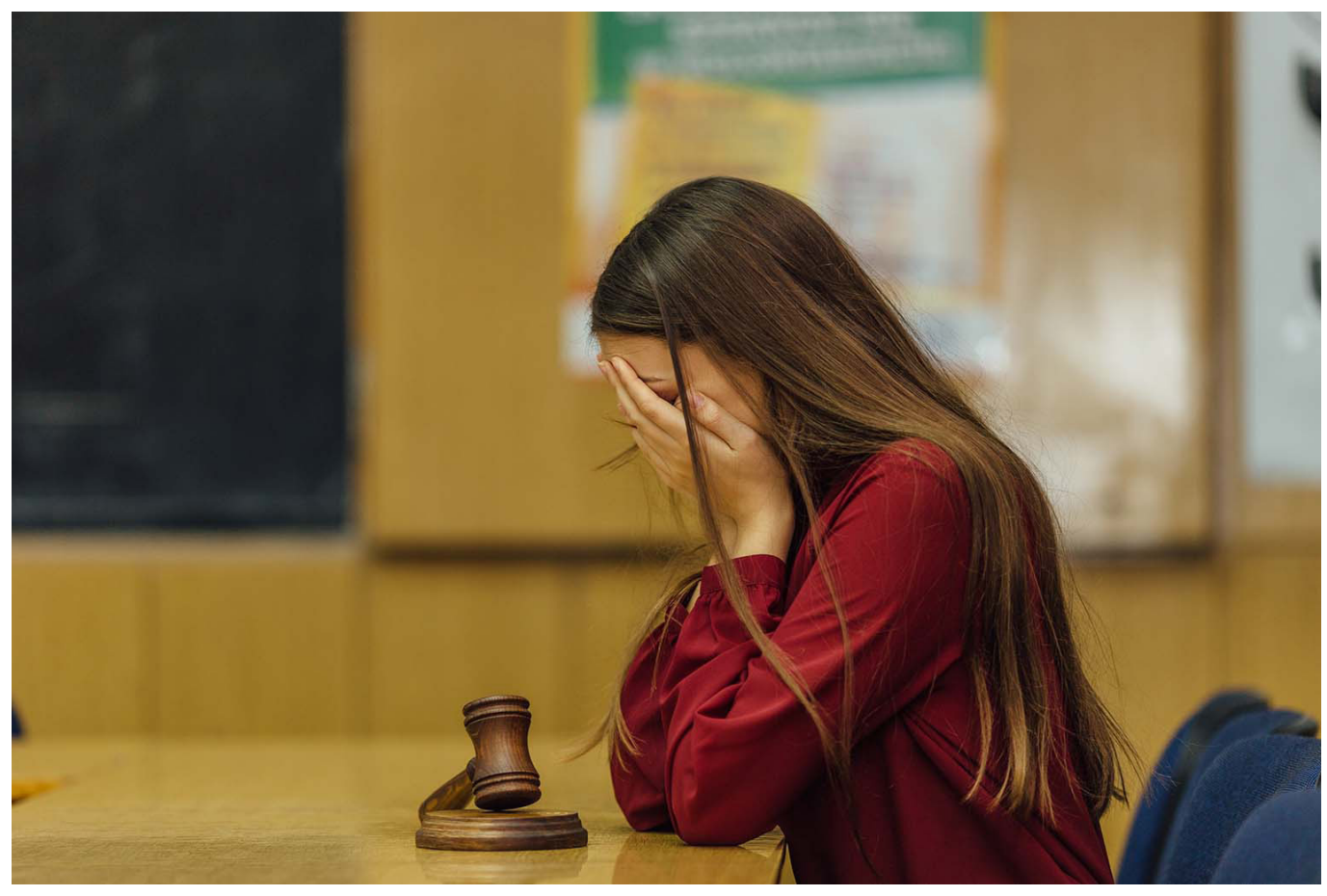

Así, existe la revictimización "cuando las autoridades muestran mayor interés en su vida privada [de la víctima] que en el esclarecimiento de los hechos y la sanción de los responsables. De esta forma, algunas autoridades administrativas y judiciales no responden con la debida seriedad y diligencia para investigar, procesar y sancionar a los responsables" (Organización de Estados Americanos [OEA], 2006-2007, parr. 19). En la legislación mexicana, la Ley General de Víctimas menciona en su artículo $5^{\circ}$ que la victimización secundaria se refiere a que:

Las características y condiciones particulares de lavíctima no podrán ser motivo para negarle su calidad. El Estado tampoco podrá exigir mecanismos o procedimientos que agraven su condición ni establecer requisitos que obstaculicen e impidan el ejercicio de sus derechos ni la expongan a sufrir un nuevo daño por la conducta de los servidores públicos (DOF, 2013).

Sin embargo, el hecho de que muchas de las denuncias de delitos contra mujeres y niñas no sean procesadas debidamente o queden impunes nos muestra ya una enorme traba: se banaliza y minimiza el problema de la violencia contra las mujeres.

Aunado a este temor de la culpabilización e indiferencia de las autoridades, la misma sociedad también influye en el problema. En muchos lugares y comunidades se percibe de forma negativa a una mujer que sufrió abuso, se la rechaza, incluso sus parejas y familiares no las aceptan después de un ataque sexual: "La víctima mujer usualmente encuentra que su persona misma y su estilo de vida están en juicio" (Doerner y Lab, 2012, p. 14). De esta forma, se pierde de vista a los verdaderos perpetradores, al proceso y la investigación necesarios para que el delito no quede impune. 
El Estado mexicano tiene la obligación internacional de respetar la Convención Interamericana para Prevenir, Sancionar y Erradicar la Violencia contra la Mujer, conocida también como la Convención Belém do Pará (1994), ${ }^{5}$ que en el capítulo ı menciona que el Estado debe abstenerse de cualquier violencia contra la mujer y velar para que sus autoridades y funcionarios se comporten en conformidad. Aún más, está obligado a tomar las medidas apropiadas, incluyendo leyes, para abolir o modificar prácticas que respalden la tolerancia de la violencia contra la mujer.

En consecuencia, el Estado debe adoptar de manera progresiva una legislación y programas de educación para modificar patrones socioculturales de conducta, con el fin de "contrarrestar prejuicios y costumbres y todo otro tipo de prácticas que se basen en la premisa de la inferioridad o superioridad de cualquiera de los géneros o en los papeles estereotipados para el hombre y la mujer que legitimizan o exacerban la violencia contra la mujer" (Convención Belém do Pará, 1994, artículo 8). Como se había mencionado, la falta de educación acerca de la igualdad de género tiene un rol importante en la revictimización de la mujer y es algo tan interiorizado en la cultura que, a veces, es difícil notarlo. Y es la obligación del Estado combatirlo, con legislación, políticas, protocolos efectivos de seguimiento de la ley y programas de educación que hablen de la igualdad de la mujer y sensibilicen a personas, de todas las edades, respecto al machismo y micromachismos existentes en la cultura mexicana.

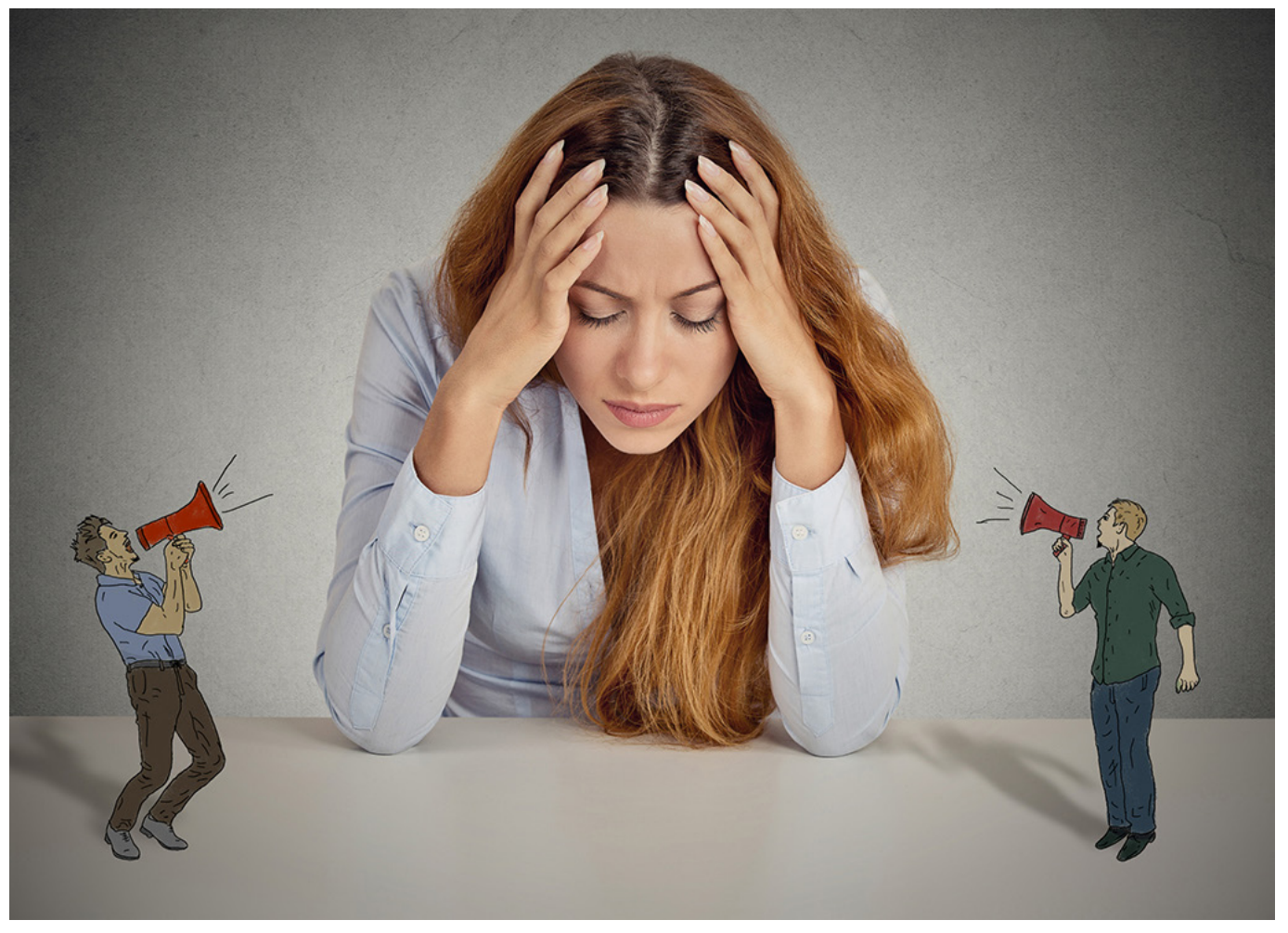


${ }^{6}$ Hay una iniciativa en Facebook de dos mujeres mexicanas de exponer encabezados con tintes machistas: se llama La Corregidora (@ corrigiendotitulares).

${ }^{7}$ Algunas notas que nos hablan de este tema las podemos encontrar en Revictimización y vulneración del proceso: ¿Cómo afectan las filtraciones la investigación de una violación? y cndh pide a medios sensibilidad con víctimas de violencia.

${ }^{8}$ A continuación, dos artículos que incluyen direcciones $y$ páginas web de ongs enfocadas a ayudar a mujeres: Fundaciones que luchan por erradicar la violencia en contra de la mujer y 10 organizaciones que brindan apoyo a las mujeres mexicanas. Además el Directorio nacional de

organizaciones de la sociedad civil con acciones hacia las muieres, publicado por el Instituto Nacional de las Mujeres.
Por un lado, es importante no perder de vista que la policía y funcionarios dedicados a la administración de justicia juegan un papel importante al evitar la revictimización de las mujeres. Para ello, capacitarlos en igualdad de género y eliminación de la violencia contra la mujer es primordial. Por otro lado, los medios de comunicación también tienen un papel central en la revictimización. Muchas veces hemos leído encabezados como "La acosada que no pidió ayuda" o "Hayan a mujer muerta por una piedra", que invisibilizan al hombre que las privó de la vida; o "Manifestaciones feministas desencadenan el suicidio de un profesor", que culpa a las víctimas o a las personas que las; y otros encabezados que cambian la narrativa de lo que realmente pasó. ${ }^{6}$ Además, los medios de comunicación han mostrado irresponsabilidad contra la víctima al publicar sus fotografías de forma abierta, muchas veces incluso del delito sexual que vivieron. Lo irónico es que normalmente sí cubren las imágenes del presunto culpable.

De esta manera, el Estado tiene, una vez más, la obligación de crear legislación y políticas que gradualmente alienten a los medios de comunicación a elaborar directrices adecuadas de difusión que contribuyan a erradicar la violencia contra la mujer en todas sus formas (Convención Belém do Pará, 1994, artículo 8). Es más sencillo que las políticas públicas que buscan la igualdad de género y erradicar pensamientos antifeministas funcionen si los medios de comunicación las apoyan, porque, queramos o no, son un poder fáctico.

Afortunadamente, ya podemos ver iniciativas que están buscando evitar la revictimización de las mujeres. Muchas organizaciones no gubernamentales (ONGS) han impulsado que las mujeres no sean revictimizadas durante los procesos penales ya que, como se ha visto, muchas veces son en éstos donde se trata a la víctima mujer como si ella hubiese ocasionado o realizado el delito. Asimismo, la importancia que tiene la sociedad civil organizada en la lucha contra la revictimización de mujeres es alta. En ocasiones, además de las comisiones de derechos humanos, las organizaciones no gubernamentales ${ }^{8}$ son los únicos lugares a los que pueden asistir las mujeres, sin perjuicios.

En el mismo sentido, las investigaciones en la academia en favor de la no revictimización de las mujeres también ayudan a visibilizar el problema:

La investigación feminista, la cual ha sido una fuerza impulsora importante para explicar la victimización de las mujeres, enfatiza que la victimización se ratifica a través de estructuras de poder que colocan a los hombres sobre las mujeres y son apoyados por el patriarcado cultural (Zaykowski y Campagna, 2014, p. 457).

Entre más estudios se encuentren de este problema, menos podrá ser ignorado y sus posibles soluciones tendrán que ser impulsadas. También es necesario que en el futuro existan aún más estudios feministas en Latinoamérica con el enfoque multidisciplinario que nos brinda la victimología.

La batalla de la igualdad de la mujer está lejos de completarse. Aún ahora en diversos lugares del mundo seguimos viendo cómo los procuradores de justicia y la sociedad en general tienden a revictimizar a las mujeres. Tenemos 
que garantizar la debida diligencia de los procesos de justicia, que los delitos de género sean atendidos adecuadamente, y que durante todo proceso de impartición de justicia con servidores públicos, éstos busquen no revictimizar a la víctima. Además, ayudaría mucho impartir programas de victimología y género para los policías y servidores públicos porque, como se mencionó, también tiene que existir una educación oportuna para evitar revictimizar a una mujer y para erradicar ideas discriminatorias que afectan la igualdad de género.

Concluyo este texto con una reflexión de la importancia de incrementar la visibilidad de los derechos de las víctimas, de estar conscientes de lo que sufren aún después del acto criminal. Hay que evitar juzgarlas sin conocer toda la historia. El saber que hay una serie de problemas para las mujeres en el acceso a la justicia y ubicar cuáles son los puntos que se deben mejorar nos ayudará a que: el sistema impartidor de justicia se gane la confianza de las mujeres víctimas, el legislador incluya más teorías de victimología y género en sus propuestas de leyes; la sociedad se concientice del daño que puede hacer con comentarios y acciones negativas contra víctimas mujeres, y a que los medios de comunicación adopten directrices internas enfocadas a la no revictimización. Así, en un futuro, podremos brindar a las víctimas mujeres de crímenes, como agresiones sexuales, violencia familiar, acoso laboral, entre muchísimos otros, una protección más amplia y estructural.

\section{Referencias}

* Asamblea General de la Organización de las Naciones Unidas. (1985, 29 de noviembre). Declaración sobre los principios fundamentales de justicia para las víctimas de delitos y del abuso de poder, resolución 40/34. https://www.unodc.org/ pdf/compendium/compendium_2006_es_part_03_02.pdf

* Convención Belém do Pará [Convención Interamericana para Prevenir, Sancionar y Erradicar la Violencia contra la Mujer]. (1994, 9 de junio). https://www.oas.org/ juridico/spanish/tratados/a-61.html

- Dignan, J. (2005). Understanding Victims and Restorative Justice. Open University Press.

Doerner, William G. y Lab, Steven P. (2011). Victimology [6ª edición]. Anderson Publishing.

* Diario Oficial de la Federación (Dof). (2013). Ley General de Víctimas. https://www. gob.mx/cms/uploads/attachment/file/112957/Ley_General_de_Victimas.pdf

* Diario Oficial de la Federación (DOF). (2015). Modelo Integral de Atención a Víctimas. https://dof.gob.mx/nota_detalle.php?codigo=5395286\&fecha=04/06/2015

* Karmen, A. (2012). Crime victims: an introduction to victimology [8 edición]. Wadsworth Cengace Learning. 
* Organización de Estados Americanos (oEA) [Comisión Interamericana de Derechos Humanos]. (2006-2007). Acceso a la justicia para las mujeres víctimas de violencia en las Américas. https://www.cidh.oas.org/pdf\%20files/Informe\%20Acceso\%20a\%20 la\%20Justicia\%20Espanol\%20020507.pdf

- upv/ehu. (2016, 14 de diciembre). ¿Qué es la Victimología? [video]. YouTube. https:// www.youtube.com/watch?v=XI-NOQhQmxO

Van Dijk, J. J. M. (1997). Towards a Research-based Crime Reduction Policy. Crime Prevention as a Cost-effective Policy Option. European Journal on Criminal Policy and Research, 5, 13-27. Dol: https://doi.org/10.1007/BF02677647

Zaykowski, H. y Campagna, L. (2014). Teaching theories of victimology. Journal of Criminal Justice Education, 25(4), 452-467. Dol: https://doi.org/10.1080/10511253.20 $\underline{14.965410}$

\section{Cómo citar el artículo}

* Carranco, Dalia B. (2020). La no revictimización de las mujeres en México. Revista Digital Universitaria (RDU), 21(4) julio-agosto. Dol: http://doi.org/10.22201/ cuaieed.16076079e.2020.21.4.3

Recepción: 26/04/2020. Aceptación: 22/05/2020 